\title{
Tuberculosis seroprevalence and comparison of hematology and biochemistry parameters between seropositive and seronegative captive Asian elephants of Nepal
}

\author{
Jeewan THAPA ${ }^{1) \# *}$, Susan K. MIKOTA ${ }^{2) \#, ~ K a m a l ~ P r a s a d ~ G A I R H E ~}{ }^{3)}$, \\ Sarad PAUDEL ${ }^{4)}$, Dinesh Kumar SINGH ${ }^{5}$, (shwwari Prasad DHAKAL ${ }^{6}$, \\ Chie NAKAJIMA ${ }^{1,7)}$ and Yasuhiko SUZUKI ${ }^{1,7)}$ \\ 1)Division of Bioresources, Research Center for Zoonosis Control, Hokkaido University, Sapporo, Hokkaido \\ 001-0020, Japan \\ ${ }^{2)}$ Elephant Care International, Hohenwald, TN 38462, USA \\ ${ }^{3)}$ Department of National Parks and Wildlife Conservation, Chitwan National Park, Chitwan, Nepal \\ 4) Department of Pathobiology and Diagnostic Investigation, College of Veterinary Medicine, Michigan State \\ University, East Lansing, MI 48828, USA \\ ${ }^{5)}$ Institute of Agriculture and Animal Science, Tribhuvan University, Paklihawa, Rupandehi, Nepal \\ ${ }^{6)}$ Agriculture and Forestry University, Rampur, Chitwan, Nepal \\ 7)International Collaboration Unit, Research Center for Zoonosis Control, Hokkaido University, Sapporo, \\ Hokkaido 001-0020, Japan
}

J. Vet. Med. Sci.

83(8): 1278-1283, 2021

doi: 10.1292/jvms.21-0113

Received: 23 February 2021

Accepted: 24 May 2021

Advanced Epub:

9 June 2021
ABSTRACT. We conducted a tuberculosis (TB) serosurveillance program of captive elephants in Nepal and compared hematology and biochemistry parameters between seropositive and seronegative elephants. A total of 153 elephants (male $=20$, female $=133$ ) from four national parks were tested for TB using the ElephantTB STAT-PAK Assay (ChemBio Diagnostic Systems, Inc., Medford, NY, USA). The mean reported age for 138 elephants was 38.5 years (range 2-71 years). Seroprevalence for TB was $21.56 \%$ (33/153). The majority of seropositive elephants were female $(n=30)$ and from Chitwan National Park $(n=29)$. The occurrence of TB seropositive cases in other more remote national parks suggests TB may be widespread among the captive elephant population of Nepal. Hematology and biochemistry analyses were performed on 13 and 22 seropositive elephants, respectively and, nine elephants from a seronegative TB herd for comparison. Hematology parameters (hemoglobin, packed cell volume, platelet, white blood cells, and erythrocyte sedimentation rate) were comparable between the two groups. Total protein, globulin, and lactate dehydrogenase were significantly higher in seronegative elephants, and bilirubin was significantly higher in seropositive elephants whereas blood urea nitrogen, creatinine, glutamic oxaloacetic transaminase/aspartate aminotransferase (GOT/AST), glutamic pyruvic transaminase/alanine aminotransferase (GPT/ALT), gamma glutamyl transferase (GT), and albumin were not significantly different. The range of biochemical parameters that were significantly different between seropositive and seronegative elephants had narrow ranges. Thus, the potential of these parameters as a direct biomarker for TB diagnosis is limited based on the findings in this study. We recommend including blood parameters in future TB surveillance studies.

KEY WORDS: biochemistry, elephant, hematology, seroprevalence, tuberculosis

Tuberculosis (TB) has been recognized as an important health problem of captive Asian elephants (Elephas maximus). Asian elephants are mainly reported to be affected and the majority of cases are due to Mycobacterium tuberculosis, a causative agent of human TB [19, 22]. Culture-confirmed cases and TB seroprevalence rates in captive elephants have been reported from several Asian elephant range countries: Nepal [20, 25-27], Thailand [2-3, 35], India [36], Malaysia [24], and Laos [12]. TB has also been reported in captive elephants from USA [22, 23], Australia [37], Sweden [13], and Japan [39], suggesting a worldwide distribution. M. tuberculosis has been isolated from dead wild Asian elephants in India [5, 40] and Sri Lanka [28] and may be an emerging threat to endangered wild populations.

*Correspondence to: Thapa, J.: jeewan@czc.hokudai.ac.jp

\#These authors contributed equally to this work.

O2021 The Japanese Society of Veterinary Science

This is an open-access article distributed under the terms of the Creative Commons Attribution Non-Commercial No Derivatives (by-nc-nd) License. (CC-BY-NC-ND 4.0: https://creativecommons.org/licenses/by-nc-nd/4.o/) 
Early diagnosis of TB in elephants can be difficult. The majority of elephants infected with TB do not show any clinical signs until the disease is advanced when weight loss, weakness, anorexia, and decreased physical activity may be observed [19, 22]. The intradermal tuberculin test used to diagnose TB in domestic livestock is not accurate in elephants [19, 22]. Isolation of the TB organism from culture of samples collected using a trunk wash technique is considered the gold standard but has several limitations, such as difficulty in handling the trunk to obtain a proper sample, poor sample quality due to contamination, and low case detection rate (largely due to intermittent shedding) [21].

Recently developed serological assays are an alternative to screen elephants for TB. The ElephantTB STAT-PAK ${ }^{\circledR}$ Assay (ChemBio Diagnostic Systems, Inc., Medford, NY, USA) which utilizes a cocktail of selected M. tuberculosis antigens and a conventional lateral-flow method, was licensed by the United States Department of Agriculture in 2007 [15, 16]. The DPP VetTB ${ }^{\circledR}$ Assay licensed in 2012, replaced the ElephantTB STAT-PAK ${ }^{\circledR}$. The DPP allows the test sample and antigen-detecting agent to be delivered independently and includes two test lines containing CFP/ESAT-6 and MPB83 antigens. The two tests show comparable results [8]. There is inter-species as well as intra-species variation in the degree and type of antigen recognition by TB-infected animals, but elephants have been shown to have a robust response to serological response primarily to CFP10/ESAT-6 [17].

Studies in human patients with active TB have shown that the red blood cell (RBC) count, hemoglobin (Hb), platelet count, and mean platelet volume are reduced [10, 29, 38]. A combined platelet count and albumin (plateletcrit-albumin) scoring model associated with increased platelet count and decreased albumin had high sensitivity to detect active TB [14]. The importance of the routine blood hematology and biochemical parameters for assessing health status is recognized, however, they have not typically been used as biomarkers for TB because of the complex physiology of TB [18, 29, 31].

Although reference values for hematology and biochemistry parameters in clinically healthy elephants are published [4, 7, 11, 33], information comparing these parameters between TB-infected and TB-suspect elephants is limited. In a study from a North American facility, the albumin:globulin ratio, mean cell hemoglobin concentration (MCHC), and glucose were found to be significantly lower in TB culture-positive elephants $(n=4)$ whereas other hematology and biochemistries parameters were not significantly different [9]. In a previous study in 2006 from Nepal, no significant association was found between hematology and biochemistry parameters and TB culture results [6]. However, this previous study considered 10 of a total 108 tested elephants to be culture positive based on acid fast positive results, and only four of 10 culture positive elephants were reported to be infected with $M$. tuberculosis based on the niacin test result, thus showing limitation in accurate identification of TB positive elephants.

There are approximately 250 captive elephants in Nepal that are used for wildlife management, conservation research, and eco-tourism. Captive elephants frequently interact with wild elephants and share grazing areas with other wildlife, providing the opportunity for transmission of TB from infected elephants to other hosts, including humans. Assessing the health and monitoring the TB status of captive elephants is critical to managing TB at the elephant-wildlife-domestic livestock-human interfaces. This study aimed to determine the seroprevalence of TB in the captive elephant population of Nepal, compare hematology and biochemistry parameters between seropositive and seronegative elephants, and determine if these parameters are of diagnostic value.

\section{MATERIALS AND METHODS}

\section{Study area and population}

This study was conducted under the Nepal Elephant Healthcare and TB Surveillance Program, a multi-stakeholder program initiated in 2007. During the study period from February 2008 to June 2009, 153 government and private owned captive elephants from the Chitwan National Park (CNP), Bardia National Park (BNP), Shuklaphanta National Park (SNP), and Parsa National Park (PNP) were screened for TB. Twenty male and 133 female elephants were evaluated. The mean reported age for 138 elephants was 38.5 years (range $2-71$ years). The ages of 15 elephants were unknown.

\section{Blood collection}

Blood was collected from a caudal auricular vein using a 19-gauge winged IV infusion sets (Jor-Vet, Jorgensen Labs, Loveland, CO, USA) and adapter (Becton-Dickinson and Co., Franklin Lakes, NJ, USA) into EDTA and serum separator tubes (Kendall, Covidien, Mansfield, MA, USA). Hematology and biochemistry analyses were performed within 9 hr of blood collection in most cases; in three cases (elephants from SNP and BNP) serum was frozen at $-20^{\circ} \mathrm{C}$ and EDTA blood was stored at $4{ }^{\circ} \mathrm{C}$ for 5 days until analysis.

\section{ElephantTB Stat-Pak ${ }^{\circledR}$ Assay}

The ElephantTB Stat-Pak ${ }^{\circledR}$ Assay was performed according to the manufacturer's instructions. Briefly, one full drop (30 $\left.\mu 1\right)$ of serum and 3 drops (about $100 \mu \mathrm{l}$ ) of the diluent were added to the sample (S) well. The result was read after 20 min. The results were interpreted as seropositive or seronegative according to the presence or absence of a blue solid line in the test ( $\mathrm{T})$ area followed by a positive line in the control (C) area.

\section{Hematological and biochemistry examination}

Biochemistry analysis was performed using serum from 22 TB seropositive elephants (female $=19$, male $=3$, average age 43 years, and age range 14-70 years) from CNP $(n=18), \operatorname{BNP}(n=2)$, SNP $(n=1)$, and PNP $(n=1)$. Hematology analysis was performed on 13 seropositive elephants (female $=11$, male $=2$, average age $=44.3$ years, and age range $14-70$ years) from $\operatorname{CNP}(n=9), B N P(n=2), S N P$ $(n=1)$, and PNP $(n=1)$. As a comparison, biochemistry and hematology analyses were performed on nine seronegative elephants 
(female $=7$, male $=2$, average age 36.3 years, and age range $6-51$ years) from a captive facility within CNP in which the entire herd $(n=9)$ was seronegative. This elephant herd was located in a remote part of the park and had infrequent interaction with other elephant herds. Blood analysis was conducted in the pathology laboratory of B.P Koirala Memorial Cancer Hospital in Chitwan, Nepal. Hematology parameters (hemoglobin, packed cell volume, platelet, white blood cells, and erythrocyte sedimentation rate), except for the erythrocyte sedimentation rate (ESR) were analyzed using a Pentra XL 80 auto analyzer (Horiba). The biochemistry profiles [(Blood urea nitrogen (BUN), creatinine, bilirubin total, glutamic oxaloacetic transaminase/aspartate aminotransferase (GOT/AST), glutamic pyruvic transaminase/alanine aminotransferase (GPT/ALT), Gamma glutamyl transferase (GT), lactate dehydrogenase, total protein, albumin, and globulin) were analyzed using a Dimension RxL autoanalyzer (Dade Behring). The ESR was performed using the wintrobe tube method with 22 seropositive and 63 seronegative elephants in the field laboratory at the Biodiversity Conservation Center of the National Trust for Nature Conservation.

\section{Data analysis}

The data was analyzed using Microsoft excel program. The association of TB seroprevalence and hematology and biochemistry parameters was analyzed using the $t$-test.

\section{RESULTS}

\section{Seroprevalence of elephants for tuberculosis}

Of 153 elephants tested during the study period, 33 (21.56\%) elephants were seropositive for TB using the Elephant TB Stat-Pak Assay. The majority of TB seropositive elephants were from CNP ( $=29)$ (Table 1). Thirty of 153 female elephants and 3 of 20 male elephants were seropositive (Table 2). The mean reported age for 31 seropositive elephants was 41.25 years (range 14-59 years). The ages of two seropositive elephants were unknown. The mean reported age for 124 seronegative elephants was 37.63 years (range 2-71 years). The ages of 13 seronegative elephants were unknown. Elephant age was not found to be associated with TB seroreactivity in this study $(P>0.05)$.

\section{Hematology and biochemistry analysis}

The tested hematology parameters (hemoglobin, packed cell volume, platelet count, white blood cell count, and erythrocyte sedimentation rate) were not significantly different $(P>0.5)$ between TB seropositive and seronegative elephants (Table 3$)$. The biochemistry parameters of bilirubin $(0.31 \pm 0.04$ and $0.27 \pm 0.02)$, total protein $(8.2 \pm 0.57$ and $8.72 \pm 0.61)$, and lactate dehydrogenase $(245.59 \pm 117.65$ and $368.11 \pm 64.23)$ were significantly different $(P<0.05)$ between TB seropositive and seronegative elephants, whereas BUN, creatinine, GOT/AST, GPT/ALT, gamma GT, and albumin were not significantly different. The difference of globulin $(6.75 \pm 0.57$ and $7.42 \pm 0.66)$ between the two groups of elephants was highly significant $(P<0.01)$, and the mean value of albumin was higher in the TB seronegative group, indicating that total protein value may be an early indicator for TB (Table 4). The difference between the mean ESR values of the seropositive $(48.3 \pm 11 \mathrm{~mm} / \mathrm{hr})$ and seronegative $(49.7 \pm 10.5$ $\mathrm{mm} / \mathrm{hr}$ ) groups was not statistically significant $(P>0.05)$.

\section{DISCUSSION}

In this study, we report the TB serology results of 153 captive elephants in Nepal tested from February 2008 to June 2009 . We found that 33 (21.56\%) elephants were seropositive using the ElephantTB Stat-Pak ${ }^{\circledR}$ Assay. Similar seropositive rates have been reported in captive elephants in Malaysia 15.87\% (10/63) [24], Thailand 30\% (18/60) [35], and Laos 36\% (29/80) [12].

Although the majority of seropositive elephants were from CNP $(n=29)$, there were cases in other national parks. This suggests TB may be widespread among the captive elephant population of Nepal. We found a higher seroprevalence of 22.3\% (29/130) among elephants from CNP compared to a 2006 study in which 13\% (15/115) of CNP elephants were seropositive, and 12 seropositive elephants were common in both studies [20]. The majority of seropositive elephants were female $(n=30,90 \%)$ when compared to males $(n=3,10 \%)$, but gender was not directly associated with TB seroprevalence in this study. Although the age of elephants was not significantly associated with serological status, the average age of seropositive elephants (41.25 years) was slightly higher than seronegative elephants (32.7 years) $(P=0.25)$ suggesting older elephants may be susceptible to TB in Nepal.

In another study from Nepal [26], six deceased elephants had TB antibody responses months to years before culture-confirmed TB diagnosis, indicating the usefulness of serosurveillence for TB in elephants.

Hematology values [hemoglobin, Packed cell volume (PCV), platelet, total white blood cells (WBC) count, and erythrocyte sedimentation rate (ESR)] were not significantly different between TB seropositive and seronegative elephants $(P>0.05)$ and were similar to published reference values $[4,7,11,33]$. A recent study has reported that TB-infected elderly elephants have lower hemoglobin than the reference values related to the physiology of iron in chronic TB infections [30]. We found similar hemoglobin values in both our groups which were also similar in age and may not have been in the chronic stage of TB infection. The ESR is considered a non-specific indicator of inflammation and infection and can be an indicator of pulmonary TB infection in humans [1], usually associated with chronic infection [34]. We did not find an association between the ESR and seroreactivity in our study. Our results show that bilirubin, total protein, and lactate dehydrogenase (LDH) values were significantly different $(P<0.05)$; and globulin value was highly significantly different $(P<0.01)$ between the two groups of elephants. The lower total protein and globulin values in TB seropositive elephants are likely due to infection with TB although nutritional status and parasite 
Table 1. Seroprevalence of tuberculosis in captive elephants in four national parks of Nepal

\begin{tabular}{lcccc}
\hline \multirow{2}{*}{ Location } & \multicolumn{3}{c}{ ElephantTB Stat-Pak ${ }^{\circledR}$ Assay } & \multirow{2}{*}{ Total } \\
\cline { 2 - 4 } & SeroNegative & SeroPositive & Invalid test & \\
\cline { 2 - 4 } & \multicolumn{3}{c}{ Number (\%) } \\
\hline Chitwan National Park & 96 & 29 & 5 & $130(84.9)$ \\
Bardia National Park & 10 & 2 & & $12(7.84)$ \\
Parsa National Park & 4 & 1 & $5(3.26)$ \\
Shuklaphanta National Park & 5 & 1 & $6(3.92)$ \\
\hline Total & $115(75.16)$ & $33(21.56)$ & $5(3.2)$ & $153(100)$ \\
\hline
\end{tabular}

TB, tuberculosis.

Table 2. Association of sex with seroprevalence of tuberculosis in captive elephants of Nepal

\begin{tabular}{lccccc}
\hline \multirow{2}{*}{ Sex } & \multicolumn{4}{c}{ ElephantTB Stat-Pak ${ }^{\circledR}$ Assay } & \multirow{2}{*}{$P$-value } \\
\cline { 2 - 4 } & Negative & \multicolumn{2}{c}{ Positive } & Invalid test & Total \\
\cline { 2 - 4 } Male & 16 & \multicolumn{4}{c}{ Number (\%) } \\
Female & 99 & 3 & 1 & $20(13.07)$ & 0.74 \\
\hline Total & $115(75.16)$ & $33(21.56)$ & $5(3.26)$ & $153(100)$ & \\
\hline
\end{tabular}

$\mathrm{TB}$, tuberculosis.

Table 3. Comparison of hematology value of tuberculosis seropositive and seronegative elephants

\begin{tabular}{lcccccccc}
\hline \multirow{2}{*}{ Parameters } & \multicolumn{4}{c}{ Seropositive } & & \multicolumn{3}{c}{ Seronegative } \\
\cline { 2 - 3 } & $\mathrm{N}$ & Range & Mean \pm SD & & $\mathrm{N}$ & Range & Mean \pm SD \\
\hline Hemoglobin $(\mathrm{Hb}) \mathrm{g} / \mathrm{dl}$ & 13 & $12.5-15.1$ & $13.26 \pm 0.68$ & & 9 & $9.7-14.0$ & $12.66 \pm 1.33$ \\
PCV $(\%)$ & 13 & $34-43$ & $36.76 \pm 2.51$ & & 9 & $27-39$ & $35.01 \pm 3.45$ \\
Platelet count $\left(/ \mathrm{mm}^{3}\right)$ & 13 & $183,000-668,000$ & $387,636.4 \pm 136,476.6$ & & 9 & $282,000-550,000$ & $419,000 \pm 77,857$ & 0.22 \\
WBC $\left(/ \mathrm{mm}^{3}\right)$ & 13 & $8,000-75,000$ & $19,292.31 \pm 17,247.53$ & & 9 & $11,900-18,800$ & $14,944.44 \pm 2,396.93$ & 0.46 \\
ESR $(\mathrm{mm} / \mathrm{hr})$ & 22 & $19-58$ & $49.3 \pm 10.5$ & & 63 & $6-61$ & $49.4 \pm 10.7$ & 0.91 \\
\hline
\end{tabular}

PCV, packed cell volume; WBC, white blood cells; ESR, erythrocyte sedimentation rate; SD, standard deviation.

Table 4. Comparison of biochemistry values between tuberculosis seropositive and seronegative elephants

\begin{tabular}{|c|c|c|c|c|c|}
\hline \multirow{2}{*}{ Parameters } & \multicolumn{2}{|c|}{ Seropositive $(n=22)$} & \multicolumn{2}{|c|}{ Seronegative $(n=9)$} & \multirow{2}{*}{$P$-value } \\
\hline & Range & Mean \pm SD & Range & Mean \pm SD & \\
\hline BUN (mg/dl) & $2.0-8.0$ & $9.78 \pm 3.53$ & $7.0-13.0$ & $10.06 \pm 2.17$ & 0.82 \\
\hline Creatinine (mg/dl) & $0.6-1.6$ & $1.06 \pm 0.22$ & $0.8-1.2$ & $0.96 \pm 0.12$ & 0.22 \\
\hline Bilirubin total (mg/dl) & $0.23-0.40$ & $0.31 \pm 0.04$ & $0.22-0.32$ & $0.27 \pm 0.02$ & $0.03 *$ \\
\hline GOT/AST (U/l) & $12.0-40.0$ & $23.45 \pm 7.24$ & $18-36$ & $26 \pm 6.36$ & 0.36 \\
\hline GPT/ALT (U/l) & $11.0-19.0$ & $14.5 \pm 1.94$ & $13-16$ & $14.33 \pm 1.00$ & 0.81 \\
\hline GammaGT (U/1) & $2.0-18.0$ & $8.71 \pm 4.54$ & $7.0-24.0$ & $11.33 \pm 5.12$ & 0.19 \\
\hline Lactate dehydrogenase (U/l) & $70-570$ & $245.59 \pm 117.65$ & $254-452$ & $368.11 \pm 64.23$ & $0.02 *$ \\
\hline Total protein $(\mathrm{g} / \mathrm{dl})$ & $7.0-10.0$ & $8.20 \pm 0.57$ & $8.0-10.0$ & $8.72 \pm 0.61$ & $0.03 *$ \\
\hline Albumin (g/dl) & $0.9-1.7$ & $1.45 \pm 0.22$ & $1.1-1.5$ & $1.30 \pm 0.14$ & 0.07 \\
\hline Globulin (g/dl) & $6.0-8.0$ & $6.75 \pm 0.57$ & $6.4-8.7$ & $7.42 \pm 0.66$ & $0.009^{* *}$ \\
\hline
\end{tabular}

$* P<0.05, * * P<0.01$. BUN, blood urea nitrogen; GOT/AST, glutamic oxaloacetic transaminase/aspartate aminotransferase; GPT/ALT, glutamic pyruvic transaminase/alanine aminotransferase; GammaGT, Gamma glutamyl transferase; SD, standard deviation; U/l, units/liter.

load may also affect these values. However, albumin was found to be slightly higher in TB seropositive elephants $(P=0.7)$. Further monitoring of total protein, globulin, and albumin is necessary to know their association with elephant TB. We found that LDH was significantly higher in TB seronegative elephants, although LDH is reported to be associated with inflammation and is higher in human TB patients [32]. We also found a significant elevation of bilirubin in TB seropositive elephants while ALT, AST, BUN, 
and creatinine were not significantly different between the groups, indicating that liver function and kidney function tests may not be directly related with elephant TB in this study. Further monitoring of LDH and bilirubin levels in elephants is necessary to better understand association with TB infection in elephants. Many factors including stages of TB infection, age groups, reproductive status, nutrition, husbandry practices, and other medical conditions may affect these blood profiles. Our findings suggest that low total protein and globulin show a correlation to TB in captive elephants of Nepal. However, we should point out that the range of certain biochemical parameters that were significantly different between seropositive and seronegative elephants did have narrow ranges (for example bilirubin, globulin, and total protein). Thus, the potential of these parameters as a direct biomarker for TB diagnosis is limited in this study. Furthermore, we should cautiously interpret these parameters as these analyses were conducted at one time point between two groups of elephants that did not differ in their apparent clinical health. Further studies from captive elephants of Nepal and other captive elephants from different geographic locations should be conducted to accurately assess these blood parameters to monitor elephant TB.

One of the important limitations of serosurveillence of elephant TB is its inability to determine the clinical stage of TB disease in elephants. The ElephantTB Stat-Pak ${ }^{\circledR}$ Assay cannot distinguish between active and latent TB infection. Most of the seropositive elephants in this study were in apparent good health and their body condition scores were similar to seronegative elephants, but the state of TB disease was unknown. We recommend assessing these blood parameters in TB culture-positive elephants to further elucidate their diagnostic value. We recommend further studies to accurately assess association of LDH and bilirubin with TB.

In conclusion, we report that $33(21.56 \%)$ of captive elephants from four national parks were seropositive for TB. The TB prevalence rate is increasing in the captive population in Nepal suggesting ongoing TB transmission. In conjunction with serological testing, blood parameters may be useful in determining TB status in elephants and should be included in elephant TB surveillance programs.

CONFLICTS OF INTEREST. The authors have nothing to disclose.

ACKNOWLEDGMENTS. We acknowledge National the Nepal's Department of National Parks and Wildlife Conservation (DNPWC), National Trust for Nature Conservation (NTNC), and WWF-Nepal Program for their kind support and co-operation for this project. We are thankful to Barbara Vincent, Chitra Bahadur Khadka, Purushottam Pandey, and Kiran Rijal for helping with sample collection from elephants. We are also thankful to Dr. Chin Bahadur Pun for helping in laboratory works. Finally, we would like to thank all the elephant care and management staff for their co-operation in this study.

\section{REFERENCES}

1. Al-Marri, M. R. and Kirkpatrick, M. B. 2000. Erythrocyte sedimentation rate in childhood tuberculosis: is it still worthwhile? Int. J. Tuberc. Lung Dis. 4: 237-239. [Medline]

2. Angkawanish, T., Morar, D., van Kooten, P., Bontekoning, I., Schreuder, J., Maas, M., Wajjwalku, W., Sirimalaisuwan, A., Michel, A., Tijhaar, E. and Rutten, V. 2013. The elephant interferon gamma assay: a contribution to diagnosis of tuberculosis in elephants. Transbound. Emerg. Dis. 60 Suppl 1: 53-59. [Medline] [CrossRef]

3. Angkawanish, T., Wajjwalku, W., Sirimalaisuwan, A., Mahasawangkul, S., Kaewsakhorn, T., Boonsri, K. and Rutten, V. P. 2010. Mycobacterium tuberculosis infection of domesticated Asian elephants, Thailand. Emerg. Infect. Dis. 16: 1949-1951. [Medline] [CrossRef]

4. Brown, I. R. F. and White, P. T. 1980. Elephant blood hematology and chemistry. Comp. Biochem. Physiol. 65B: 1-12.

5. Chandranaik, B. M., Shivashankar, B. P., Umashankar, K. S., Nandini, P., Giridhar, P., Byregowda, S. M. and Shrinivasa, B. M. 2017. Mycobacterium tuberculosis infection in free-roaming wild Asian elephant. Emerg. Infect. Dis. 23: 555-557. [Medline] [CrossRef]

6. Giri, K., Kaufman, G. E. and Dhakal, I. P. 2011. The relationship between blood parameter and mycobacterium culture status in captive elephants of Nepal. Nepalese. Vet. J. 30: 119-129.

7. Gromadzka-Ostrowska, J., Jakubów, K., Zalewska, B. and Krzywicki, Z. 1988. Haematological and blood biochemical studies in female domesticated Indian elephants (Elaphas maximus L.). Comp. Biochem. Physiol. A Comp. Physiol. 89: 313-315. [Medline] [CrossRef]

8. Greenwald, R., Lyashchenko, O., Esfandiari, J., Miller, M., Mikota, S., Olsen, J. H., Ball, R., Dumonceaux, G., Schmitt, D., Moller, T., Payeur, J. B., Harris, B., Sofranko, D., Waters, W. R. and Lyashchenko, K. P. 2009. Highly accurate antibody assays for early and rapid detection of tuberculosis in African and Asian elephants. Clin. Vaccine Immunol. 16: 605-612. [Medline] [CrossRef]

9. Harr, K., Isaza, R. and Harvey, J. 2001. Clinicopathologic findings in Mycobacterium tuberculosis culture-positive elephants (Elephas maximus) in comparison to clinically normal elephants. pp. 209-211. Proceeding of American Association of Zoo Veterinarians, American Association of Wildlife Veterinarians, Association of Reptilian and Amphibian Veterinarians and National Association of Wildlife Veterinarians joint conference, Omaha.

10. Huang, S., Yi, F. M., Zhou, R., Chen, M., Lei, Y., Zhao, J. Z., Zhang, H. and Xia, B. 2013. The utility of platelet, mean platelet volume, and red cell distribution width in the diagnosis of active Crohn's disease and intestinal tuberculosis. Saudi Med. J. 34: 1161-1166. [Medline]

11. Janyamethakul, T., Sripiboon, S., Somgird, C., Pongsopawijit, P., Panyapornwithaya, V., Klinhom, S., Loythong, J. and Thitaram, C. 2017. Hematologic and biochemical reference intervals for captive Asian elephants (Elephas maximus) in Thailand. Kafkas Univ. Vet. Fak. Derg. 4: $665-669$.

12. Lassausaie, J., Bret, A., Bouapao, X., Chanthavong, V., Castonguay-Vanier, J., Quet, F., Mikota, S. K., Théorêt, C., Buisson, Y. and Bouchard, B. 2015. Tuberculosis in Laos, who is at risk: the mahouts or their elephants? Epidemiol. Infect. 143: 922-931. [Medline] [CrossRef]

13. Lewerin, S. S., Olsson, S. L., Eld, K., Röken, B., Ghebremichael, S., Koivula, T., Källenius, G. and Bölske, G. 2005. Outbreak of Mycobacterium tuberculosis infection among captive Asian elephants in a Swedish zoo. Vet. Rec. 156: 171-175. [Medline] [CrossRef]

14. Li, K., Liu, S. X., Yang, C. Y., Jiang, Z. C., Liu, J., Fan, C. Q., Li, T., Dong, X. M., Wang, J. and Ran, R. Y. 2019. A routine blood test-associated predictive model and application for tuberculosis diagnosis: a retrospective cohort study from northwest China. J. Int. Med. Res. 47: $2993-3007$. [Medline] [CrossRef] 
15. Lyashchenko, K. P., Greenwald, R., Esfandiari, J., Mikota, S., Miller, M., Moller, T., Vogelnest, L., Gairhe, K. P., Robbe-Austerman, S., Gai, J. and Waters, W. R. 2012. Field application of serodiagnostics to identify elephants with tuberculosis prior to case confirmation by culture. Clin. Vaccine Immunol. 19: 1269-1275. [Medline] [CrossRef]

16. Lyashchenko, K. P., Greenwald, R., Esfandiari, J., Olsen, J. H., Ball, R., Dumonceaux, G., Dunker, F., Buckley, C., Richard, M., Murray, S., Payeur, J. B., Andersen, P., Pollock, J. M., Mikota, S., Miller, M., Sofranko, D. and Waters, W. R. 2006. Tuberculosis in elephants: antibody responses to defined antigens of Mycobacterium tuberculosis, potential for early diagnosis, and monitoring of treatment. Clin. Vaccine Immunol. 13: 722-732. [Medline] [CrossRef]

17. Lyashchenko, K. P., Gortázar, C., Miller, M. A. and Waters, W. R. 2018. Spectrum of antibody profiles in tuberculous elephants, cervids, and cattle. Vet. Microbiol. 214: 89-92. [Medline] [CrossRef]

18. Mikota, S. K. 2006. Hemolymphatic system. pp. 326-324. In: Biology, Medicine and Surgery of Elephants (Fowler, M. E. and Mikota, S. K. eds.), Blackwell Publishing Professional, Ames.

19. Mikota, S. K. and Maslow, J. N. 2011. Tuberculosis at the human-animal interface: an emerging disease of elephants. Tuberculosis (Edinb.) 91: 208-211. [Medline] [CrossRef]

20. Mikota, S. K., Gairhe, K., Giri, K., Hamilton, K., Miller, M., Paudel, S., Lyashchenko, K., Larson, R. S., Payeur, J. B., Waters, W. R., Greenwald, R., Dumonceaux, G., Vincent, B. and Kaufman, G. K. 2015. Tuberculosis surveillance of elephants (Elephas maximus) in Nepal at the captive-wild interface. Eur. J. Wildl. Res. 61: 219-221. [CrossRef]

21. Mikota, S. K., Lyashchenko, K. P., Lowenstine, L., Agnew, D. and Maslow, J. N. 2015. Mycobacterial Infections in Elephants. pp. 259-276. In: Many Hosts of Mycobacteria. Tuberculosis, Leprosy, and other Mycobacterial Diseases of Man and Animals. (Mukundan, H., Chambers, M.A., Waters, W.R. and Larsen, M.H. eds.), CABI Publishing House, Nosworthy Way.

22. Mikota, S. K., Peddie, L., Peddie, J., Isaza, R., Dunker, F., West, G., Lindsay, W., Larsen, R. S., Salman, M. D., Chatterjee, D., Payeur, J., Whipple, D., Thoen, C., Davis, D. S., Sedgwick, C., Montali, R. J., Ziccardi, M. and Maslow, J. 2001. Epidemiology and diagnosis of Mycobacterium tuberculosis in captive Asian elephants (Elephas maximus). J. Zoo Wildl. Med. 32: 1-16. [Medline]

23. Miller, M. A., Finnegan, M., Storms, T., Garner, M. and Lyashchenko, K. P. 2018. Outbreak of Mycobacterium tuberculosis in a herd of captive Asian elephants (Elephas maximus): antemortem diagnosis, treatment, and lessons learned. J. Zoo Wildl. Med. 49: 748-754. [Medline] [CrossRef]

24. Ong, B. L., Ngeow, Y. F., Razak, M. F., Yakubu, Y., Zakaria, Z., Mutalib, A. R., Hassan, L., Ng, H. F. and Verasahib, K. 2013. Tuberculosis in captive Asian elephants (Elephas maximus) in Peninsular Malaysia. Epidemiol. Infect. 141: 1481-1487. [Medline] [CrossRef]

25. Paudel, S., Mikota, S. K., Nakajima, C., Gairhe, K. P., Maharjan, B., Thapa, J., Poudel, A., Shimozuru, M., Suzuki, Y. and Tsubota, T. 2014. Molecular characterization of Mycobacterium tuberculosis isolates from elephants of Nepal. Tuberculosis (Edinb.) 94: 287-292. [Medline] [CrossRef]

26. Paudel, S., Mikota, S. K., Thapa, J., Lyashchenko, K. P., Gairhe, K. P., Dhakal, I. P., Subedi, N., Maharjan, B., Subedi, S., Kaufman, G. and Tsubota, T. 2018. Serodiagnosis of elephant tuberculosis: a useful tool for early identification of infected elephants at the captive-wild interface. Eur. J. Wildl. Res. 64: 70. [CrossRef]

27. Paudel, S., Nakajima, C., Mikota, S. K., Gairhe, K. P., Maharjan, B., Subedi, S., Poudel, A., Sashika, M., Shimozuru, M., Suzuki, Y. and Tsubota, T. 2019. Mixed Mycobacterium tuberculosis Lineage Infection in 2 Elephants, Nepal. Emerg. Infect. Dis. 25: 1031-1032. [Medline] [CrossRef]

28. Perera, B. V. P., Salgadu, M. A., Gunawardena, G. S. P. S., Smith, N. H. and Jinadasa, H. R. N. 2014. First confirmed case of fatal tuberculosis in a wild Sri Lankan Elephant. Gajah 41: 28-31.

29. Rohini, K., Surekha Bhat, M., Srikumar, P. S. and Mahesh Kumar, A. 2016. Assessment of hematological parameters in pulmonary tuberculosis patients. Indian J. Clin. Biochem. 31: 332-335. [Medline] [CrossRef]

30. Ruetten, M., Steinmetz, H. W., Thiersch, M., Kik, M., Vaughan, L., Altamura, S., Muckenthaler, M. U. and Gassmann, M. 2020. Iron regulation in elderly Asian elephants (Elephas maximus) chronically infected with Mycobacterium tuberculosis. Front. Vet. Sci. 7: 596379. [Medline] [CrossRef]

31. Sahin, F., Yazar, E. and Yıldız, P. 2012. Prominent features of platelet count, plateletcrit, mean platelet volume and platelet distribution width in pulmonary tuberculosis. Multidiscip. Respir. Med. 7: 38. [Medline] [CrossRef]

32. Samanta, S., Sharma, A., Das, B., Mallick, A. K. and Kumar, A. 2016. Significance of total protein, albumin, globulin, serum effusion albumin gradient and LDH in the differential diagnosis of pleural effusion secondary to tuberculosis and cancer. J. Clin. Diagn. Res. 10: BC14-BC18. [Medline]

33. Silva, I. D. and Kuruwita, V. Y. 1993. Hematology, plasma, and serum biochemistry values in domesticated elephants (Elephas maximus ceylonicus) in Sri Lanka. J. Zoo Wildl. Med. 24: 440-444.

34. Schulman, H., Niward, K., Abate, E., Idh, J., Axenram, P., Bornefall, A., Forsgren, S., Jakobsson, J., Öhrling, C., Kron, M., Brudin, L., Diro, E., Getachew Kebede, A., Paues, J., Bruchfeld, J., Wejse, C., Stendahl, O. and Schön, T. 2019. Sedimentation rate and suPAR in relation to disease activity and mortality in patients with tuberculosis. Int. J. Tuberc. Lung Dis. 23: 1155-1161. [Medline] [CrossRef]

35. Songthammanuphap, S., Puthong, S., Pongma, C., Buakeaw, A., Prammananan, T., Warit, S., Tipkantha, W., Kaewkhunjob, E., Yindeeyoungyeon, W. and Palaga, T. 2020. Detection of Mycobacterium tuberculosis complex infection in Asian elephants (Elephas maximus) using an interferon gamma release assay in a captive elephant herd. Sci. Rep. 10: 14551. [Medline] [CrossRef]

36. Verma-Kumar, S., Abraham, D., Dendukuri, N., Cheeran, J. V., Sukumar, R. and Balaji, K. N. 2012. Serodiagnosis of tuberculosis in Asian elephants (Elephas maximus) in Southern India: a latent class analysis. PLoS One 7: e49548. [Medline] [CrossRef]

37. Vogelnest, L., Hulst, F., Thompson, P., Lyashchenko, K. P. and Herrin, K. A. 2015. Diagnosis and management of tuberculosis (Mycobacterium tuberculosis) in an Asian elephant (Elephas maximus) with a newborn calf. J. Zoo Wildl. Med. 46: 77-85. [Medline] [CrossRef]

38. Weber, S. F., Bélard, S., Rai, S., Reddy, R., Belurkar, S. and Saravu, K. 2017. Immune thrombocytopenia secondary to tuberculosis: a case and review of literature. Int. J. Tuberc. Lung Dis. 21: 466-470. [Medline] [CrossRef]

39. Yoshida, S., Suga, S., Ishikawa, S., Mukai, Y., Tsuyuguchi, K., Inoue, Y., Yamamoto, T. and Wada, T. 2018. Mycobacterium caprae Infection in Captive Borneo Elephant, Japan. Emerg. Infect. Dis. 24: 1937-1940. [Medline] [CrossRef]

40. Zachariah, A., Pandiyan, J., Madhavilatha, G. K., Mundayoor, S., Chandramohan, B., Sajesh, P. K., Santhosh, S. and Mikota, S. K. 2017. Mycobacterium tuberculosis in Wild Asian Elephants, Southern India. Emerg. Infect. Dis. 23: 504-506. [Medline] [CrossRef] 